\begin{tabular}{|c|c|c|c|}
\hline \multirow{3}{*}{$\begin{array}{r}\text { Case Reports in } \\
\text { Gastroenterology }\end{array}$} & \multirow{2}{*}{\multicolumn{2}{|c|}{ Case Rep Gastroenterol 2019;13:398-402 }} & \multirow[b]{3}{*}{$\begin{array}{l}\text { Karger } \\
\text { Open'access }\end{array}$} \\
\hline & & & \\
\hline & $\begin{array}{l}\text { DOI: } 10.1159 / 000503170 \\
\text { Published online: September 25, } 2019\end{array}$ & $\begin{array}{l}\text { (c) } 2019 \text { The Author(s) } \\
\text { Published by S. Karger AG, Basel } \\
\text { www.karger.com/crg }\end{array}$ & \\
\hline & $\begin{array}{l}\text { This article is licensed under the } \mathrm{Cr} \\
\text { International License (CC BY-NC) (ht } \\
\text { Usage and distribution for commercial }\end{array}$ & $\begin{array}{l}\text { nons Attribution-NonCommercial } 4.0 \\
\text { ger.com/Services/OpenAccessLicense). } \\
\text { uires written permission. }\end{array}$ & \\
\hline
\end{tabular}

\title{
Crohn's Disease Presenting as Granulomatous Appendicitis
}

\author{
Ryota Otsuka $^{a}$ Koichi Shinoto ${ }^{a}$ Yasushi Okazaki Kota Sato $^{a}$ \\ Atsushi Hirano $^{\text {a }}$ Tetsuro Isozaki ${ }^{a}$ Tomohide Tamachi ${ }^{a}$ Tomoya Hirai ${ }^{a}$ \\ Shohei Yonemoto ${ }^{a}$ Hisahiro Matsubara $^{\mathrm{b}}$ \\ aDepartment of Surgery, Yokohama Rosai Hospital, Yokohama City, Japan; bepartment of \\ Frontier Surgery, Graduate School of Medicine, Chiba University, Chiba, Japan
}

\section{Keywords}

Appendix · Granulomatous appendicitis · Crohn's disease · Appendectomy

\begin{abstract}
Granulomatous appendicitis is uncommon. It can be caused by infectious or systemic disorders, such as Crohn's disease (CD) and sarcoidosis. It is therefore essential to investigate systematic causes of granulomatous appendicitis after surgery by appropriate examinations. It is also rare for acute appendiceal inflammation to develop due to active CD. We herein report a case of $C D$ presenting as granulomatous appendicitis. The patient was a 28 -year-old man who arrived at the emergency room with right lower abdominal pain. Computed tomography showed a low-density lesion with a clear boundary and a small high-density spot in its center behind the cecum. Acute appendicitis with abscess formation was suspected and conservative treatment was started. After 3 consecutive days of conservative treatment there was no improvement in his condition. We therefore performed open appendectomy. Histopathological examination showed numerous noncaseous epithelioid granulomas in the wall of the appendix. Specific staining revealed no evidence of acid-fast bacilli or fungi. During follow-up after discharge, colonoscopy demonstrated erosion from the cecum to the transverse colon. A colon biopsy showed severe inflammation with cryptitis, Paneth cells, and a granulomatous lesion. The patient was therefore diagnosed with $C D$ and treatment with mesalazine was started. Careful examination is necessary to diagnose and properly treat patients with granulomatous inflammation of the appendix.




\section{Introduction}

Granulomatous appendicitis is a rare disease [1,2]. It can be caused by infections, including Mycobacterium tuberculosis, Yersinia pseudotuberculosis, parasites, and fungi or have noninfectious causes, such as Crohn's disease (CD) or sarcoidosis [1]. It is therefore essential to systematically investigate the causes of granulomatous appendicitis after surgery by performing appropriate examinations. Granulomatous appendicitis is considered to be a manifestation of $\mathrm{CD}$, and approximately $5-10 \%$ of patients with granulomatous appendicitis have been reported to develop CD [3].

$\mathrm{CD}$ is a chronic inflammatory disease that affects all parts of the gastrointestinal tract, from the mouth to the anus. However, it is rare for active CD to cause acute inflammation of the appendix [4]. We herein report a case of CD presenting as granulomatous appendicitis.

\section{Case Report}

A 28-year-old man presented to the emergency room with right lower abdominal pain that had persisted for 2 weeks. His past and family histories were unremarkable. On examination, he had right abdominal pain without muscular resistance, with a temperature of $38.8^{\circ} \mathrm{C}$, a blood pressure of 144/92 $\mathrm{mm} \mathrm{Hg}$, and a pulse of 108 beats/min. His white blood cell count was $15,200 / \mu \mathrm{L}$ and his C-reactive protein level $14.60 \mathrm{mg} / \mathrm{dL}$. Computed tomography showed a low-density lesion with a clear boundary and a small high-density spot in its center behind the cecum (Fig. 1). Based on these findings, acute appendicitis with abscess formation was suspected and conservative treatment using antibiotics was started. His condition showed no improvement after 3 consecutive days of conservative treatment; thus, we performed open surgery. First, mobilization of the cecum was performed and the abscess was released. The appendix was inflamed and adhered to the ascending colon. Appendectomy with drainage of the abscess was performed. Operative time was $126 \mathrm{~min}$ and blood loss was $203 \mathrm{~mL}$.

Histopathological examination revealed prominent lymphoid hyperplasia and numerous noncaseous epithelioid granulomas in the wall of the appendix (Fig. 2). Specific staining revealed no evidence of acid-fast bacilli or fungi. Culture of pus taken intraoperatively for microbiological evaluation grew Streptococcus constellatus.

The patient made an uneventful recovery without paralytic ileus and was discharged on postoperative day 14. During follow-up after discharge, the patient underwent a T SPOT assay, which excluded the presence of tuberculosis. Total-body computed tomography revealed no signs of sarcoidosis. Total colonoscopy demonstrated erosion from the cecum to the transverse colon. A biopsy from the terminal ileum revealed chronic inflammation with lymphocyte-based inflammatory cells, and a biopsy specimen from the colon showed severe inflammation with cryptitis, Paneth cells, and granulomatous lesions (Fig. 3). Based on these findings, he was diagnosed with $\mathrm{CD}$ and started on treatment with mesalazine.

\section{Discussion}

Granulomatous inflammation of the appendix is rare, with a reported frequency of $<2 \%$ in appendectomy specimens $[1,2]$. It can caused by infections, including M. tuberculosis, $Y$. pseudotuberculosis, parasites, and fungi or have noninfectious causes, such as diverticulitis, foreign body reactions, tumor, $\mathrm{CD}$, and sarcoidosis [1]. Idiopathic granulomatous appendicitis 
is a very rare disease. There are many reports of granulomatous inflammation of the appendix associated with CD.

CD is a chronic inflammatory condition of the gastrointestinal tract. CD found in the appendix is generally classified into two types. One is appendiceal $\mathrm{CD}$, which only develops in the appendix; the other is appendiceal involvement of $\mathrm{CD}$, in which inflammation spreads to the appendix in patients with cecum and ileum-type CD [5]. Meyerding and Bertram [6] reported the first case of isolated appendiceal CD in 1953. The incidence is reported to be 0.1$2.0 \%$ [7]. Appendiceal CD is associated with a lower rate of recurrence and a better prognosis than CD developing in other gastrointestinal sites [8,9]. Distinguishing between idiopathic granulomatous appendicitis and appendiceal CD is not easy, and long-term follow-up may be necessary. On the other hand, the incidence of appendiceal involvement of CD is reported to be $25 \%$ and the recurrence rate in patients with this condition is reported to be $15-20 \%$ $[4,10]$.

Our patient was considered to have colorectal-type $\mathrm{CD}$ based on the colon biopsy results and was asymptomatic for a long time prior to hospitalization. Although he developed typical symptoms of acute appendicitis for the first time, abdominal pain and diarrhea are considered to be the initial symptoms of $C D$, and it is rare for acute inflammation to first develop in the appendix in patients with active CD [4]. Therefore, he underwent appendectomy with drainage of the abscess under a clinical diagnosis of acute appendicitis. Since his pathological results showed granulomatous inflammation of the appendix, we could detect CD in the early stage by performing a detailed examination after the operation and start treatment promptly. CD is reported as an etiology in approximately $0.128-0.4 \%$ of patients who undergo appendectomy with a diagnosis of acute appendicitis [5]. Although rare, CD may cause acute appendicitis; thus, careful examination of pathological specimens after appendectomy is necessary.

In summary, we described a case of $\mathrm{CD}$ presenting as granulomatous appendicitis. We should suspect $\mathrm{CD}$ and need to perform detailed examinations to facilitate its diagnosis and treatment when patients present with granulomatous inflammation of the appendix.

\section{Acknowledgement}

We thank Brian Quinn from Japan Medical Communication for editing a draft of this paper.

\section{Statement of Ethics}

Written informed consent was obtained from the patient for publication of this case report and any accompanying images. Ethics approval was not needed for this paper.

\section{Disclosure Statement}

The authors have no conflicts of interest to disclose.

\section{Funding Sources}

No funding was received specifically for this case report. 
Otsuka et al:: Crohn's Disease Presenting as Granulomatous Appendicitis

\section{Author Contributions}

K. Sato, A. Hirano, T. Isozaki, T. Tamachi, T. Hirai, S. Yonemoto, and R. Otsuka made, analyzed, and interpreted our patient's imaging examinations. K. Shinoto and R. Otsuka demonstrated surgery for our patient. The manuscript was prepared by R. Otsuka under the supervision of K. Shinoto, Y. Okazaki, and H. Matsubara. All authors read and approved the final manuscript.

\section{References}

1 Mizushima T, Ito T, Mizuno H, Udatsu Y, Miyazaki Y, Imakita M, et al. Idiopathic granulomatous appendicitis treated surgically with long-term follow-up: report of a case. Surg Today. 2007;37(8):690-3.

2 Shivakumar P, Shanmugam RP, Mani CS. Idiopathic granulomatous appendicitis: a rare appendicular pseudo tumor. Trop Gastroenterol. 2010 Apr-Jun;31(2):130-1.

3 Alhambra Rodríguez de Guzmán C, Morales Marín VJ, Salvelio Picazo Yeste J, Moreno Sanz C. Granulomatous appendicitis: an uncommon cause of acute abdomen. Cir Esp. 2015 Nov;93(9):e119-21.

4 Fonkalsrud EW, Ament ME, Fleisher D. Management of the appendix in young patients with Crohn's disease. Arch Surg. 1982 Jan;117(1):11-4.

5 Kato T, Kojima T, Shimizu T, Kitashiro S, Konishi K, Yamabuki T, et al. Report of a Case with Crohn's Disease Presenting as Acute Appendicitis. Jpn J Gastroenterol Surg. 2000;33(8):1529-33.

6 Meyerding EV, Bertram HF. Nonspecific granulomatous inflammation (Crohn's disease) of the appendix; a case report. Surgery. 1953 Nov;34(5):891-4.

7 AbdullGaffar B. Granulomatous diseases and granulomas of the appendix. Int J Surg Pathol. 2010 Feb;18(1):14-20.

8 Yang SS, Gibson P, McCaughey RS, Arcari FA, Bernstein J. Primary Crohn's disease of the appendix: report of 14 cases and review of the literature. Ann Surg. 1979 Mar;189(3):334-9.

9 Ariel I, Vinograd I, Hershlag A, Olsha O, Argov S, Klausner JM, et al. Crohn's disease isolated to the appendix: truths and fallacies. Hum Pathol. 1986 Nov;17(11):1116-21.

10 Agha FP, Ghahremani GG, Panella JS, Kaufman MW. Appendicitis as the initial manifestation of Crohn's disease: radiologic features and prognosis. AJR Am J Roentgenol. 1987 Sep;149(3):515-8.

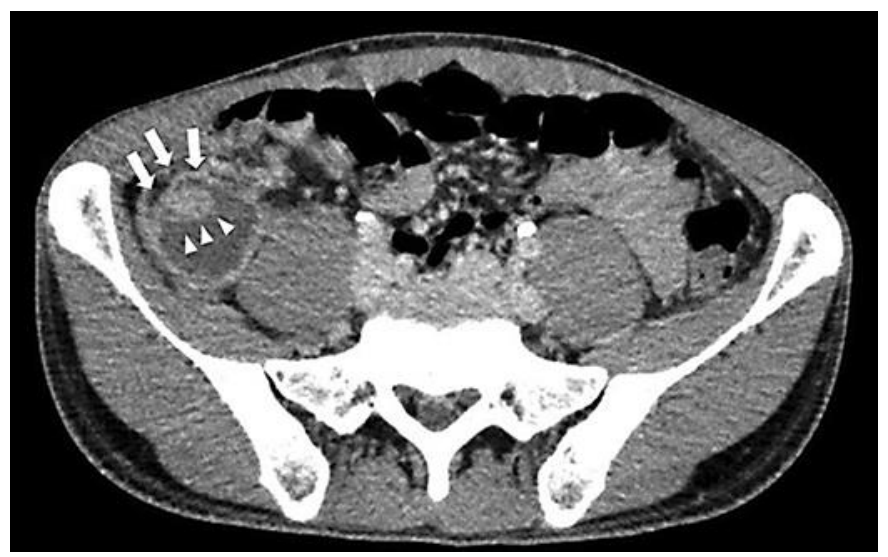

Fig. 1. Computed tomography showed a low-density lesion with a clear boundary (arrows) and a small high-density spot in its center (arrowheads) behind the cecum. 


\section{Case Reports in Gastroenterology \\ Case Rep Gastroenterol 2019;13:398-402 \\ DOI: 10.1159/000503170 \\ (c) 2019 The Author(s). Published by S. Karger AG, Basel www.karger.com/crg \\ Otsuka et al.: Crohn's Disease Presenting as Granulomatous Appendicitis}

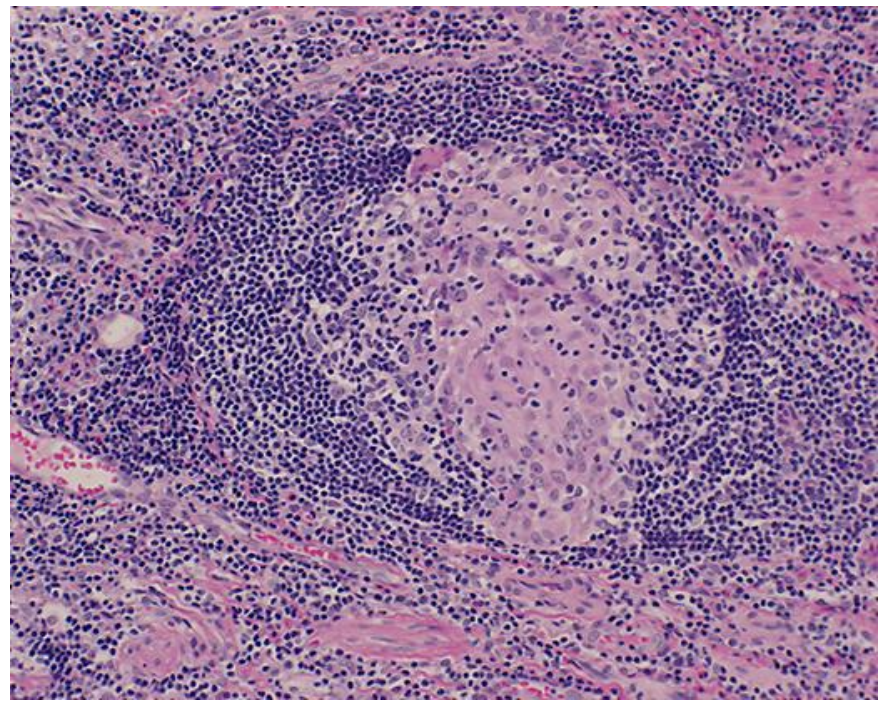

Fig. 2. Histopathological findings showed prominent lymphoid hyperplasia and numerous noncaseous epithelioid granulomas in the wall of the appendix $(\times 100)$.

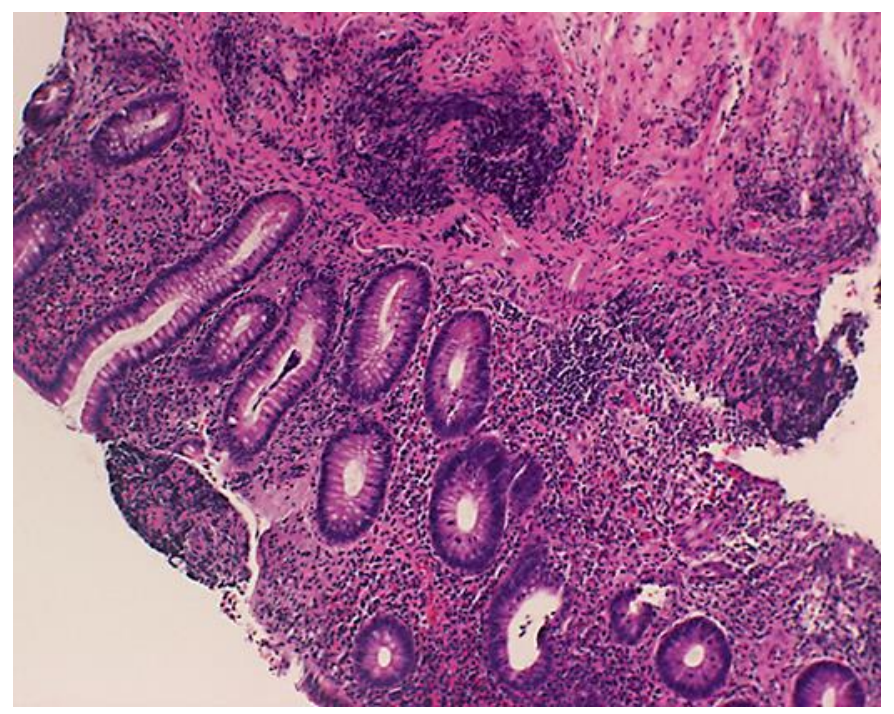

Fig. 3. The biopsy from the colon showed severe inflammation with cryptitis, Paneth cells, and granulomatous lesions $(\times 50)$. 